\title{
Influence of Penicillium aurantiogriseum and its Mycotoxin Citrinin on Haemolymph
} of Schistocerca gregaria (Forskål)

\section{E.M. Rashad ${ }^{1}$, S.S. Rashed ${ }^{1}$, G. A. Helal ${ }^{2}$ and F.M. Hashem ${ }^{1}$}

\author{
${ }^{1}$ Entomology Section, Zoology Department, Faculty of Science, Zagazig University, Zagazig, \\ Egypt. \\ ${ }^{2}$ Microbiology Department, Faculty of Science, Zagazig University, Zagazig, Egypt. \\ Received: 30 Sept. 2020 / Accepted 05 Nov. 2020 / Publication date: 15 Nov. 2020
}

\begin{abstract}
The influence of entomopathogenic fungi, Penicillium aurantiogriseum and its mycotoxin citrinin against the haemolymph of the $5^{\text {th }}$ instar nymphs of Schistocerca gregaria (Forskål) were studied under laboratory conditions. This study aims to detect the changes of some biochemical parameters of haemolymph which are valuable in evaluating and predicting the pathogenic effect on $S$. gregaria. Results showed an effect of $P$. aurantiogriseum and its mycotoxin citrinin on haemocytes, phenoloxidase activity and haemolymph protein at $1^{\text {st }}, 3^{\text {rd }}, 5^{\text {th }}, 7^{\text {th }}$ and $9^{\text {th }}$ days post application. Comparison between the two treatments revealed fluctuations in the mean total haemocyte count and detection of plasmatocytes, lymphocytes and granulocytes in different percentages in treated nymphs. Citrinin mycotoxin and P. aurantiogriseum disturbed the titre of phenoloxidase enzyme in all intervals after infection. Also, they decreased the total haemolymph protein content significantly during the five days post infection as compared to the control.
\end{abstract}

Keywords: P. aurantiogriseum, mycotoxin, S. gregaria, haemolymph, haemocytes, proteins, phenoloxidase.

\section{Introduction}

The growing demand for reducing chemical inputs in agriculture and increased resistance to insecticides have provided impetus to the development of alternative forms of insect pest control. Entomopathogenic fungi are potentially the most versatile biological control agents due to their wide host range. These fungi comprise a diverse group of over 90 genera with approximately 750 species, reported from different insects. Entomopathogenic fungi are naturally occurring organisms which are perceived as less damaging to the environment (Rai et al., 2014). Penicillium spp. was considered as entomopathogenic fungi (Al- Keridis, 2015). Mycotoxins are synthesized by fungi and released as secondary metabolites which are toxic to many insect species. Mycotoxins exhibited insecticidal effects and developmental delays to many insect species (Zeng et al., 2006) and caused rapid lethal effects to Schistocerca gregaria (Helal et al., 2012).

Insect haemolymph is the major extracellular fluid in insects. It makes up from $15 \%$ to $75 \%$ of the volume of the insect, varying significantly with species and individual physiological state. Haemolymph contains cellular components, proteins, carbohydrates, lipids and salts, which are obtained from food and circulated in haemolymph by dissolving in the aqueous (water) portion of the fluid. The haemolymph additionally bears various immunity-related products that function in protecting the insect against systemic infection. These products are components of the humoral (i.e., non-cellular) part of the insect immune system. To a large extent, the humoral effectors are inducible, i.e., they are undetectable (or nearly so) in uninfected insects, and increase to high titers in response to mechanical wounding and infection by bacteria, fungal pathogens, nematodes, etc. Phenoloxidase is one of the vitally important inducible humoral effectors which are induced very rapidly by a proteolytic cascade and anti-microbial peptides(Chapman, 2013).

In insects, the circulating haemocytes perform primary functions in the body such as phagocytosis, coagulation to prevent loss of blood, encapsulation of foreign bodies, nodule formation, detoxification of metabolites and biological active materials, as well as storage and distribution of nutritive materials to various tissues (Siddiqui and Al-Kalifa, 2012; Chavan et al., 2017). They derive from stem cells that differentiate into specific lineages. However, certain haemocyte types are not common in all insects and

Corresponding Author: F.M. Hashem, Entomology Section, Zoology Department, Faculty of Science, Zagazig University, Zagazig, Egypt. E-mail: fatma_abohashem@yahoo.com 
differ among species (Meister and Lagueux, 2003). The desert locust, Shistocerca gregaria (Orthoptera: Acrididae) (Forskål) is among the major pests of many tropical and subtropical countries causing extensive damage to the foliar part of many plants (Gesraha, 2007) particularly during years with locust outbreaks. Therefore, the objective of the current study was to assess the effect of $P$. aurantiogriseum and its mycotoxin citrinin on haemocytes, titer of phenoloxidase enzyme and total haemolymph proteins of $5^{\text {th }}$ instar nymphs of $S$. greagria.

\section{Materials and Methods}

\section{Insect culture}

Females and males of the desert locust, Schistocerca gregaria (Forskảl) were obtained from Plant Protection Research Institute, Zagazig city, Sharkia, Egypt. Adults were breed in the laboratory of Entomology Section, Zoology Department, Faculty of Science, Zagazig University, Zagazig city, Sharkia, Egypt, under crowded conditions at $30 \pm 2{ }^{\circ} \mathrm{C}, 70-80 \% \mathrm{R}$. H. and photoperiod of $8 \mathrm{D}$ : $16 \mathrm{~L}$ for several generations. Adults were placed in wooden - framed cages measuring $40 \times 40 \times 60 \mathrm{~cm}$ and provided with cups of moist sieved sand to serve as ovipositional sites as described by Hassanein (1965).

\section{Conidial production}

The conidia of the fungus previously isolated from S.gregaria cadavers by Hashem (2013) and identified as P. aurantiogriseum (Dierekx) 800 (AUMC) were harvested and prepared according to Hicks et al. (2001); Helal et al. (2019).

\section{Extraction of mycotoxin from $P$. aurantiogriseum}

Cultivation of fungi, $P$. aurantiogriseum for mycotoxin screening was conducting by: Fungal conidia on Capek's medium fortified by $2 \mathrm{~g}$ yeast extract and $10 \mathrm{~g}$ peptone of the following composition: Glucose, $10 \mathrm{~g} ; \mathrm{NaNO}_{3}, 1 \mathrm{~g} ; \mathrm{K}_{2} \mathrm{HPO}_{4}, 1 \mathrm{~g} ; \mathrm{KCl}, 0.5 \mathrm{~g} ; \mathrm{MgSO}_{4} .7 \mathrm{H}_{2} \mathrm{O}, 0.5 \mathrm{~g} ; \mathrm{FeSO}_{4} .7 \mathrm{H}_{2} \mathrm{O}, 0.01 \mathrm{~g}$; Peptone, $10 \mathrm{~g}$ and yeast extract $2 \mathrm{~g}$, per liter of distilled water. The cultivation of $P$. aurantiogriseum was made according to Helal et al. (2019).

\section{Preparation of the crude mycotoxin of $P$. aurantiogriseum}

The content of flask (medium + mycelium) was homogenized for 5 minutes in a high speed blender (16000 r.p.m.) with $100 \mathrm{ml}$ chloroform. The extraction procedure was repeated three times. The combined chloroform extract was washed with equal volume of distilled water, dried over anhydrous sodium sulphate, filtered then concentrated under vacuum or a stream of nitrogen to near dryness, and diluted to $1 \mathrm{ml}$ with chloroform. The preparation and identification of the crude mycotoxin citrinin of $P$. aurantiogriseum were accomplished according to Helal et al. (2019).

\section{Insect infection}

The experimental design was arranged with three groups of treatments and three replicates, each experiment consisted of ten $5^{\text {th }}$ instar nymphs of $S$. gregaria. The first group was inoculated with $50 \mu 1$ sterile water, the second group was inoculated with $50 \mu \mathrm{l}$ of conidial suspension of $8 \times 10^{3}$ conidia $/ \mathrm{ml}$ and the third group was inoculated with $50 \mu \mathrm{l}$ of $15 \mu \mathrm{l} / \mathrm{ml}$ citrinin mycotoxin by the topical application technique beneath the dorsal pronotal shield of nymphal instars.

\section{Haemolymph collection}

Haemolymph of $5^{\text {th }}$ instar nymphs was drawn from coxal joint by sterile micro syringe. Control and treated haemolymph samples were taken at five successive intervals of 1, 3, 5, 7 and 9 days post treatments. The collected samples $(10 \mu \mathrm{l})$ were transferred into clean dry centrifuge tubes containing a few crystals of phenylthiourea (PTU) to prevent melanization before analysis according to Al- Mokhlef (2008). The haemolymph was centrifuged at 4000 r.p.m. for $5 \mathrm{~min}$. at $4^{\circ} \mathrm{C}$. After centrifugation, the supernatant fluid was stored at $-20^{\circ} \mathrm{C}$ until analysis.

\section{Total haemocyte counts (THC)}

For haemocyte counting, $3 \mu \mathrm{l}$ of haemolymph of $5^{\text {th }}$ instar nymphs of $S$. gregaria were placed on a glass slide and smeared to a thin film. The smears were first stained with diluted May- Grundwald 
stain for 3 min., then washed with distilled water and stained for a second time with diluted Giemsa for $10 \mathrm{~min}$. then washed again in distilled water according to Guzo and Stolz (1987). The haemocytes were observed under light microscope with $\times 100$ oil immersion objectives and identified according to Gupta (1979). The total haemocyte counts was calculated by diluting haemolymph (1:4) with sterile ice cold anticoagulant buffer then placed in an improved Neubauer haemocytometer. Total haemocyte counts were counted in a standard haemocytometer according to the formula of Jones (1962):

$\frac{\text { Number of haemocyte counted per chamber } x \text { dilution } x \text { depth factor }}{\text { Number of } 1 \mathrm{~mm} \text { squares counted }}$

\section{Differential haemocyte count (DHC)}

Stained haemolymph preparations were carried out, according to Arnold and Hinks (1979). The haemolymph was smeared on clean glass slides, allowed to dry for 1 minute, and fixed for 2 minutes with drops of absolute methyl alcohol. Fixed cells were stained with Giemsa's solution (diluted 1: 20 in distilled water) for 20 minutes, washed several times with tap water, and dipped in distilled water. The stained smears were air -dried and mounted in DPX with slip cover. The haemocytes were viewed under light microscope at a magnification $10 \times 40=400$. The cell shape, cytoplasmic ratio, cytoplasmic inclusions and shape of nucleus were used for classification of haemocytes using the classification scheme of Bréhelin and Zachary (1986). The percentages of haemocyte types were calculated by the formula:

$$
\frac{\text { Number of each haemocyte type }}{\text { Total number of haemocytes examined }} \times 100
$$

\section{Phenoloxidase (PO) activity:}

Phenoloxidase activity was determined according to a modification of Ishaaya (1971), in a reaction mixture consisting of $0.5 \mathrm{ml}$ phosphate buffer $(0.1 \mathrm{M}, \mathrm{pH} 7), 200 \mu 1$ enzyme solution and 200 $\mu 1$ catechol solution ( $2 \%)$. Prior to the initiation of the reaction, the substrate and other ingredients of the reaction mixture were separately incubated at the optimum temperature of the reaction $\left(25^{\circ} \mathrm{C}\right)$. Enzyme reaction was initiated by adding catechol solution. Then after exactly $1 \mathrm{~min}$, the optical density was determined, zero adjustment was against a sample blank at 405nm on APEL-PD 303 Spectrophotometer.

\section{Determination of total haemolymph protein.}

Colorimetric determination of total haemolymph protein of $5^{\text {th }}$ instar nymphs of desert locust inoculated with $50 \mu \mathrm{l}$ of sterile water, $50 \mu \mathrm{l}$ of $8 \times 10^{3}$ conidia / ml conidial suspension of $P$. aurantiogriseum and $50 \mu \mathrm{l}$ of $15 \mu \mathrm{l} / \mathrm{ml}$ citrinin mycotoxin were carried out as described by Bradford (1976). Protein reagent was prepared by dissolving $100 \mathrm{mg}$ of Coomassie Brilliant blue G-250 in $50 \mathrm{ml}$ $95 \%$ ethanol. To this solution $100 \mathrm{ml} 85 \%(\mathrm{~W} / \mathrm{V}$ ) phosphoric acid were added. The resulting solution was diluted to a final of 1 liter. Sample solution $(50 \mu \mathrm{l})$ or for preparation of standard curve $50 \mu 1$ of serial concentrations containing 10 to $100 \mu \mathrm{g}$ bovine serum albumin were pipette into test tubes. The absorbance at $595 \mathrm{~nm}$ was measured after $2 \mathrm{~min}$. and before $1 \mathrm{hr}$ against blank prepared from $1 \mathrm{ml}$ of phosphate buffer and $5 \mathrm{ml}$ protein reagent.

\section{Statistical analysis}

Means and Standard errors of total haemolymph protein and phenoloxidase activity of $5^{\text {th }}$ instar nymphs were calculated and compared by using a one- way ANOVA in SPSS Version 14.0.

\section{Results}

\section{Total haemocyte counts (THC)}

The data in table (1) showed the effect of inoculation of $50 \mu 1$ of sterile water, $50 \mu 1$ of $8 \times 10^{3}$ conidia $/ \mathrm{ml} P$. aurantiogriseum and $50 \mu \mathrm{l}$ of $15 \mu \mathrm{g} / \mathrm{ml}$ citrinin mycotoxin on the mean THC of $5^{\text {th }}$ instar nymphs of $S$. gregaria at $1^{\text {st }}, 3^{\text {rd }}, 5^{\text {th }}, 7^{\text {th }}$ and $9^{\text {th }}$ days after treatment. On the $1^{\text {st }}$ and $3^{\text {rd }}$ days after treatment, the nymphs showed significant decrement in the THC in insects inoculated with conidial suspension and citrinin mycotoxin, respectively $(0.44 \pm 0.06,0.68 \pm 0.12 ; 0.68 \pm 0.005,0.61 \pm 0.09 \times$ 
$10^{3}$ haemocytes $\left./ \mu \mathrm{l}\right)$ as compared to control $\left(1.4 \pm 0.5,0.8 \pm 0.09 \times 10^{3}\right.$ haemocytes $\left./ \mu \mathrm{l}\right)(\mathrm{p}=0.01,0.009$ and $0.6,0.4$, respectively). Comparison between nymphs inoculated with conidial suspension and citrinin mycotoxin revealed a non-significant changes in the mean of THC at the two intervals, respectively $(p=0.35$ and 0.7$)$. The mean $\mathrm{THC}$ in the $5^{\text {th }}$ day after treatment revealed a non -significant increment in insects inoculated with $P$. aurantiogriseum and citrinin mycotoxin to reach $0.81 \pm 0.02$ and $0.9 \pm 0.19 \times 10^{3}$ haemocytes $/ \mu 1$, respectively as compared to control $\left(0.59 \pm 0.18 \times 10^{3}\right.$ haemocytes/ $\mu 1)(p=0.4$ and 0.23$)$. Also, insects inoculated with citrinin mycotoxin demonstrated a non-significant increase as compared to insects inoculated with conidial suspension $(p=0.7)$. Moreover, significant increase was recorded on the $7^{\text {th }}$ and $9^{\text {th }}$ days after treatment with $P$. aurantiogriseum $(0.98 \pm 0.07$ and $0.75 \pm 0.15 \times 10^{3}$ haemocytes/ $\mu 1$, respectively) and after treatment with citrinin mycotoxin $(1 \pm 0.14$ and $0.3 \pm 0.03 \times 10^{3}$ haemocytes/ $\left.\mu \mathrm{l}\right)$, respectivelyas compared to control $(\mathrm{p}=0.049,0.041$ and 0.029 , $0.5)$. The mean THC decreased in control insects to $0.44 \pm 0.16$ and $0.18 \pm 0.01 \times 10^{3}$ haemocytes $/ \mu 1$, respectively. The comparison between inoculated insects with conidial suspension and inoculated insects with citrinin mycotoxin revealed a non-significant changes on the $7^{\text {th }}$ and $9^{\text {th }}$ days post treatment in the mean $\mathrm{THC}(\mathrm{p}=0.7$ and 0.1 , respectively).

Table 1: Effect of conidial suspension of $P$. aurantiogriseum and its mycotoxin citrinin on mean total haemocyte counts of $5^{\text {th }}$ instar nymphs of $S$. gregaria

\begin{tabular}{cccc}
\hline Days & $\begin{array}{c}\text { Control } \\
(\text { Mean } \pm \mathbf{S E ~}) \times \mathbf{1 0}^{\mathbf{3}}\end{array}$ & $\begin{array}{c}\text { Conidial suspension } \\
(\text { Mean } \pm \mathbf{S E ~}) \times \mathbf{1 0}^{\mathbf{3}}\end{array}$ & $\begin{array}{c}\text { Citrinin mycotoxin } \\
(\mathbf{M e a n} \pm \mathbf{S E}) \times \mathbf{1 0}^{\mathbf{3}}\end{array}$ \\
\hline $\mathbf{1}$ & $1.4 \pm 0.5^{\mathrm{ab}}$ & $0.44 \pm 0.06^{\mathrm{aA}}$ & $0.68 \pm 0.12^{\mathrm{bA}}$ \\
$\mathbf{3}$ & $0.8 \pm 0.09^{\mathrm{BC}}$ & $0.68 \pm 0.005^{\mathrm{BD}}$ & $0.61 \pm 0.09^{\mathrm{CD}}$ \\
$\mathbf{5}$ & $0.59 \pm 0.18^{\mathrm{EF}}$ & $0.81 \pm 0.02^{\mathrm{EG}}$ & $0.9 \pm 0.19^{\mathrm{FG}}$ \\
$\mathbf{7}$ & $0.44 \pm 0.16^{\mathrm{dc}}$ & $0.98 \pm 0.07^{\mathrm{dD}}$ & $1.0 \pm 0.14^{\mathrm{cD}}$ \\
$\mathbf{9}$ & $0.18 \pm 0.01^{\mathrm{He}}$ & $0.75 \pm 0.15^{\mathrm{eI}}$ & $0.3 \pm 0.03^{\mathrm{HI}}$ \\
\hline
\end{tabular}

Means with the same small letters are significantly differences $\mathrm{p} \leq 0.05$ Capital letters are non- significantly differences, $\mathrm{df} 1=2, \mathrm{df} 2=6$

\section{Differential haemocytes count (DHC)}

Haemolymph of the $5^{\text {th }}$ instar nymphs of $S$. gregaria revealed the presence of three types of blood cells in control and in infected insects. Table (2) illustrated types and percentages of different haemocytes / $3 \mu \mathrm{l}$ of haemolymph of the $5^{\text {th }}$ instar nymphs inoculated with sterile water (control), conidial suspension of $P$. aurantiogriseum and citrinin mycotoxin after 1, 3, 5, 7and 9 days post treatment.

Table 2: Types and percentage of haemocytes of $5^{\text {th }}$ instar nymphs of $S$. gregaria inoculated with conidial suspension of P. aurantiogriseum and its mycotoxin citrinin

\begin{tabular}{|c|c|c|c|c|}
\hline Days & & $\begin{array}{l}\text { Plasmatocytes } \\
\text { Percentage }\end{array}$ & $\begin{array}{c}\text { Lymphocytes } \\
\text { Percentage }\end{array}$ & $\begin{array}{c}\text { Granulocytes } \\
\text { Percentage }\end{array}$ \\
\hline \multirow{5}{*}{ ن̈ } & 1 & $57 \pm 2.3^{\mathbf{A}}$ & $31.8 \pm 3.2^{\mathrm{I}}$ & $10.8 \pm 0.8^{\mathrm{b}}$ \\
\hline & 3 & $60 \pm 5^{\mathrm{B}}$ & $30 \pm 5^{\mathrm{J}}$ & $10 \pm 0^{\mathrm{E}}$ \\
\hline & 5 & $50 \pm 0.5^{\mathrm{ae}}$ & $36 \pm 1^{\mathrm{K}}$ & $13 \pm 0.5^{\mathrm{Ff}}$ \\
\hline & 7 & $53 \pm 4^{C}$ & $35 \pm 2^{\mathrm{L}}$ & $12 \pm 2^{\mathrm{G}}$ \\
\hline & 9 & $54 \pm 1^{\mathrm{D}}$ & $35 \pm 0.0^{\mathrm{M}}$ & $12.5 \pm 2.5^{\mathrm{H}}$ \\
\hline \multirow{5}{*}{ 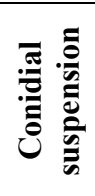 } & 1 & $58 \pm 7.5^{\mathrm{A}}$ & $27.5 \pm 5.5^{\mathrm{I}}$ & $13 \pm 1^{\mathrm{bc}}$ \\
\hline & 3 & $57 \pm 7.5^{\mathrm{B}}$ & $31.5 \pm 8.5^{\mathrm{J}}$ & $11 \pm 1^{\mathrm{E}}$ \\
\hline & 5 & $52 \pm 2.5^{\mathrm{aQ}}$ & $32.5 \pm 2.5^{\mathrm{K}}$ & $15 \pm 0^{\mathrm{Fd}}$ \\
\hline & 7 & $57 \pm 1^{\mathrm{C}}$ & $32.5 \pm 2.5^{\mathrm{L}}$ & $10 \pm 1.5^{\mathrm{G}}$ \\
\hline & 9 & $53 \pm 1.9^{\mathrm{D}}$ & $35.6 \pm 0.6^{\mathrm{M}}$ & $11 \pm 1.2^{\mathrm{H}}$ \\
\hline \multirow{5}{*}{ 罩 } & 1 & $55 \pm 3^{\mathrm{A}}$ & $36 \pm 2^{\mathrm{I}}$ & $9 \pm 1^{\mathrm{c}}$ \\
\hline & 3 & $57 \pm 0.5^{\mathrm{B}}$ & $34 \pm 2^{\mathrm{J}}$ & $8 \pm 1.5^{\mathrm{E}}$ \\
\hline & 5 & $63 \pm 2.5^{\mathrm{Qe}}$ & $27 \pm 3^{\mathrm{K}}$ & $9 \pm 0.5^{\mathrm{df}}$ \\
\hline & 7 & $57 \pm 1.5^{\mathrm{C}}$ & $33 \pm 2^{\mathrm{L}}$ & $9 \pm 0.5^{\mathrm{G}}$ \\
\hline & 9 & $52 \pm 2.5^{\mathrm{D}}$ & $34 \pm 1^{\mathrm{M}}$ & $13 \pm 1.5^{\mathrm{H}}$ \\
\hline
\end{tabular}

Means with the same small letters are significantly differences $\mathrm{p} \leq 0.05$, Capital letters are non- significantly differences, $\mathrm{df} 1=14, \mathrm{df} 2=15$. 
Plasmatocytes predominated in the haemolymph of the $5^{\text {th }}$ instar nymphs followed by lymphocytes and granulocytes in control and in infected insects. Plasmatocytes recorded the highest percentage on the $3^{\text {rd }}$ day and the lowest one on the $5^{\text {th }}$ day post inoculation with sterile water. They listed significant changes after treatment with conidial suspension and citrinin mycotoxin on the $5^{\text {th }}$ day post treatment $(\mathrm{p}=0.7$ and 0.2$)$ and non-significant differences on the other four periods as compared to control $(\mathrm{p}=$ $0.82,0.63,0.44,0.86 ; 0.6,0.63,0.39,0.7$, respectively). Haemolymph of the infected insects recorded non-significant changes in the percentage of lymphocytes at all periods after the two inoculations as compared to control $(\mathrm{p}=0.39,0.76,0.48,0.61$ and 0.89 , respectively for conidial suspension and $\mathrm{p}=$ $0.40,0.42,0.08,0.68$ and 0.84 , respectively for citrin mycotoxin). Meanwhile, the percentage of granulocytes increased on the $1^{\text {st }}$ day post treatment with conidial suspension and decreased on the $5^{\text {th }}$ day post treatment with citrinin significantly as compared to control $(p=0.23$ and 0.037$)$. Citrinin mycotoxin caused non-significant disturbance in the percentage of plasmatocytes $(p=0.5,1,0.3,0.92$ and 0.9$)$ and lymphocytes $(\mathrm{p}=0.1,0.6,0.27,0.9$ and 0.73$)$ after the five periods of inoculation as compared to conidial suspension of $P$. aurantiogriseum, respectively. On the other hand, significant decrement in granulocyte percentages was caused by the mycotoxin on the $1^{\text {st }}$ and $5^{\text {th }}$ days post treatment as compared to conidial suspension ( $\mathrm{p}=0.04$ and 0.007$)$.

\section{Phenoloxidase activity}

Phenoloxidase enzyme showed fluctuations in its activity in the haemolymph of the $5^{\text {th }}$ instar nymphs of S.gregaria inoculated with conidial suspension of $P$. aurantiogriseum and its mycotoxin citrinin at the five periods of post inoculation $\left(1^{\text {st }}, 3^{\text {rd }}, 5^{\text {th }}, 7^{\text {th }}\right.$ and $9^{\text {th }}$ days $)$ as compared to the control (Figure 1). It elevated significantly at $1^{\text {st }}$ and $9^{\text {th }}$ days $(37.3 \pm 0.32$ and $51.8 \pm 0.04 \mathrm{mg} / \mathrm{ml}, \mathrm{p}=0.29$ and 0.0 , respectively) and non- significantly at $5^{\text {th }}$ day $(37.15 \pm 0.12, \mathrm{p}=0.0)$ post inoculation with $P$. aurantiogriseum as compared to control $(19.7 \pm 0.27,17.2 \pm 1.4$ and $30.3 \pm 3.78 \mathrm{mg} / \mathrm{ml}$, respectively). The activity of phenoloxidase suppressed significantly at the $3^{\text {rd }}$ and $7^{\text {th }}$ days post inoculated instars with the conidial suspension ( $11.43 \pm 3.3$ and $14.8 \pm 0.08 \mathrm{mg} / \mathrm{ml}, \mathrm{p}=0.66$ and 0.0 , respectively) as compared to the control $(21.05 \pm 5.7$ and $36.1 \pm 1.1 \mathrm{mg} / \mathrm{ml}$, respectively).) On the other hand, the activity of phenoloxidase showed a non-significant increment in insects inoculated with citrinin mycotoxin as compared with the control on the $1^{\text {st }}$ and $3^{\text {rd }}$ days post inoculation $(22.5 \pm 0.3$ and $22.2 \pm 0.1 \mathrm{mg} / \mathrm{ml}, \mathrm{p}=$ 0.29 and 0.66 , respectively). Inversely, there was a significant decrement in the activity on the $5^{\text {th }}$ and $7^{\text {th }}$ days $(14.4 \pm 0.4$ and $22.6 \pm 0.4 \mathrm{mg} / \mathrm{ml}$, respectively, $\mathrm{p}=0.0)$ post inoculation and highly significant increase in the $9^{\text {th }}$ days $(88.6 \pm 0.2 \mathrm{mg} / \mathrm{ml}, \mathrm{p}=0.0)$ post inoculation with citrinin mycotoxin as compared to control insects. Meanwhile, citrinin mycotoxin inhibited significantly the activity of phenoloxidase as compared with the effect of conidial suspension inoculation of $P$. aurantiogriseum at $1^{\text {st }}$ and $5^{\text {th }}$ days post inoculation $(\mathrm{p}=0.0)$ and promoted its effect significantly at $3^{\text {rd }}, 7^{\text {th }}$ and $9^{\text {th }}$ days post treatment $(p=$ $0.0,0.01$ and 0.0 , respectively) as shown in figure (1).

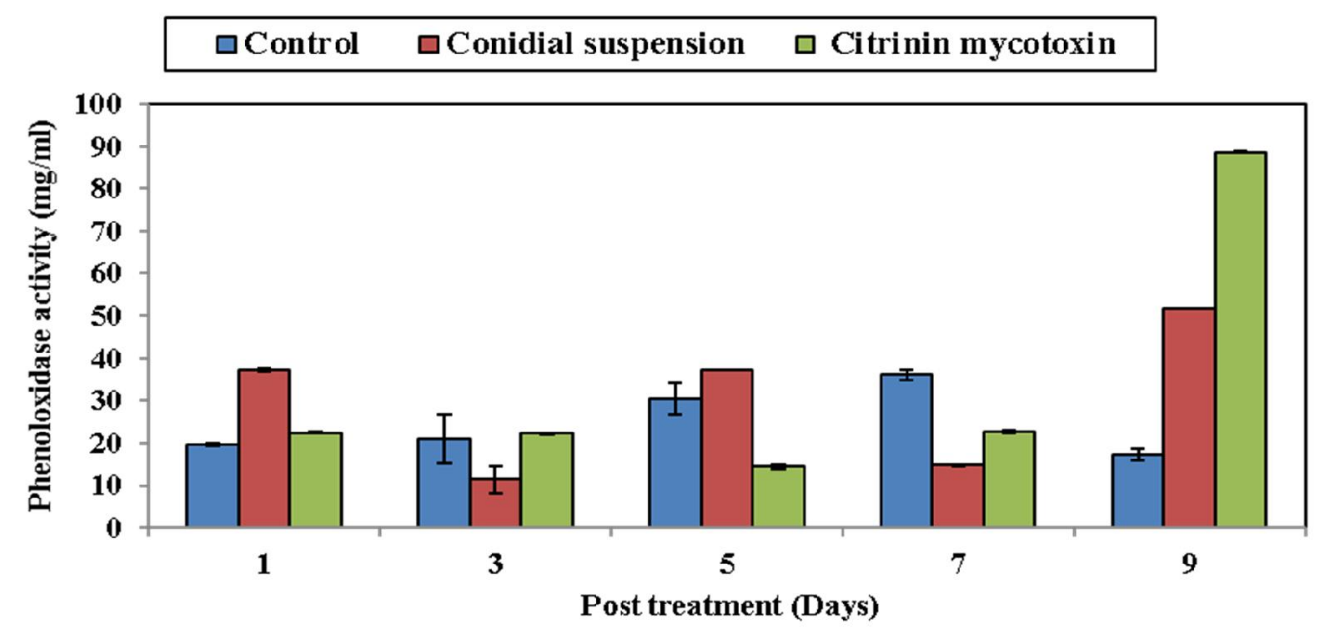

Fig. 1: The effect of conidial suspension $P$. aurantiogriseum and its mycotoxin citrinin on phenoloxidase activity $(\mathrm{mg} / \mathrm{ml})$ in haemolymph of $5^{\text {th }}$ instar nymphs of $S$. gregaria. 


\section{Total haemolymph protein content}

Obtained results in figure (2) revealed that inoculation of $5^{\text {th }}$ instar nymphs with $P$. aurantiogriseum reduced the concentration of total haemolymph protein content as compared to control instars inoculated with sterile water at different days post treatment. The total haemolymph protein content recorded a remarkable significant decrease in the $1^{\text {st }}$ day after inoculation with conidial suspension $(7.6 \pm 0.3 \mathrm{mg} / \mathrm{ml})$ as compared to control $(55 \pm 4.5 \mathrm{mg} / \mathrm{ml}, \mathrm{p}=0.006)$. The same decrease recorded on the $3^{\text {rd }}, 5^{\text {th }}, 7^{\text {th }}$ and $9^{\text {th }}$ days post treatment $(7.57 \pm 0.57,7.38 \pm 1,10.38 \pm 1$ and $6.5 \pm 0.46$ $\mathrm{mg} / \mathrm{ml}$, respectively) as compared to control $(33 \pm 4.7,24 \pm 3.3,44 \pm 5.2$ and $26 \pm 3 \mathrm{mg} / \mathrm{ml}, \mathrm{p}=0.0,0.08$, 0.0 and 0.14 , respectively). Moreover, insects inoculated with citrinin mycotoxin showed a significant decrease in total haemolymph protein content in the $1^{\text {st }}, 5^{\text {th }}, 7^{\text {th }}$ and $9^{\text {th }}$ days post inoculation $(50.7 \pm 0.67$, $13.5 \pm 1.6,9.5 \pm 0.8$ and $20.6 \pm 2 \mathrm{mg} / \mathrm{ml}$, respectively, $\mathrm{p}=0.0)$ as compared to control $(55 \pm 4.5,24 \pm$ $3.3,44 \pm 5.2$ and $26 \pm 3 \mathrm{mg} / \mathrm{ml}$, respectively) and a significant increase in the $3^{\text {rd }}$ day post inoculation $(43.5 \pm 0.11 \mathrm{mg} / \mathrm{ml})$ as compared to control $(33 \pm 4.7 \mathrm{mg} / \mathrm{ml}, \mathrm{p}=0.0)$. Meanwhile,

Total haemolymph protein contents in insects inoculated with citrinin mycotoxin revealed a highly significant increment in the $1^{\text {st }}, 3^{\text {rd }}$ and $9^{\text {th }}$ day post treatment $(50.7,43.5$, and $20.6 \mathrm{mg} / \mathrm{ml}$, respectively) as compared to insects inoculated with conidial suspension $(7.6,7.57$ and $6.5 \mathrm{mg} / \mathrm{ml}$, respectively) ( $\mathrm{p}=0.00,0.00$ and 0.002$)$. The $5^{\text {th }}$ day post inoculated insects with citrinin mycotoxin recorded a non-significant increase in total haemolymph protein content $(13.5 \pm 1.6 \mathrm{mg} / \mathrm{ml})$ as compared to inoculated insects with conidial suspension $(7.38 \pm 1.0 \mathrm{mg} / \mathrm{ml})(\mathrm{p}=0.11)$, while, total haemolymph protein content in $7^{\text {th }}$ day post treatment showed a non-significant increase in insects inoculated with conidial suspension as compared to insects inoculated with citrinin mycotoxin $(p=0.8)$ (Figure 2).

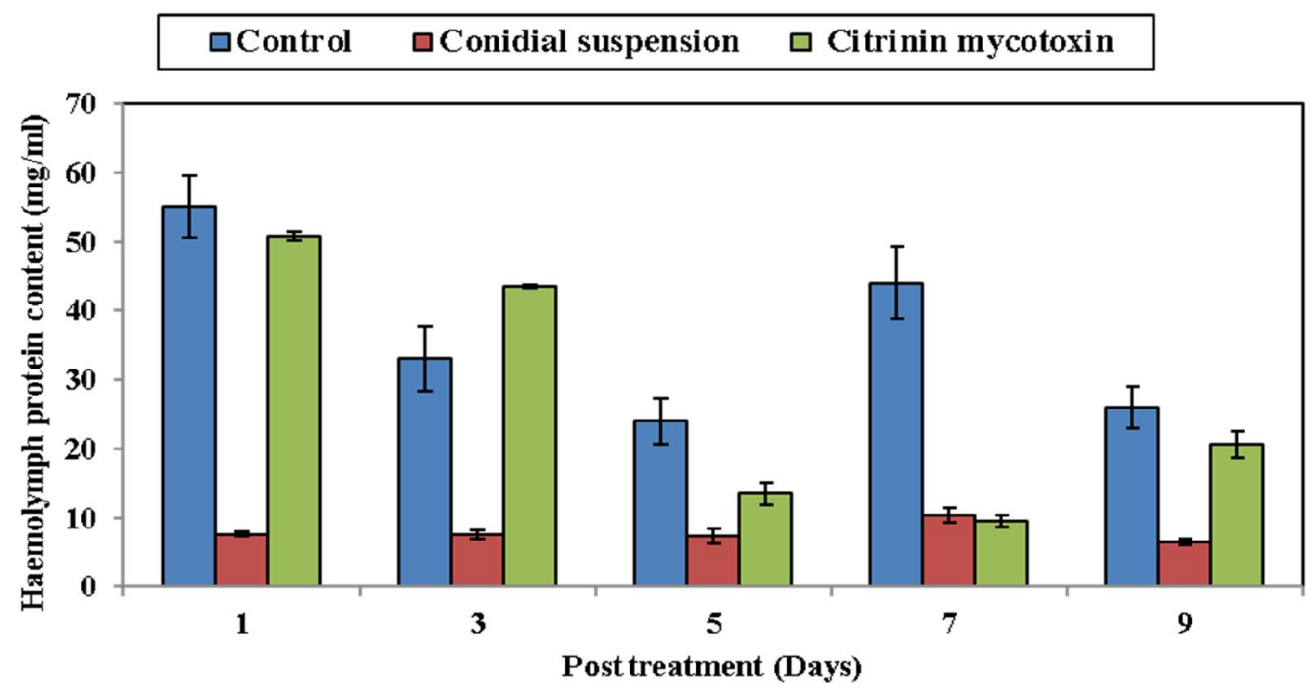

Fig. 2: Effect of conidial suspension of $P$. aurantiogriseum and its mycotoxin citrinin on total haemolymph protein content $(\mathrm{mg} / \mathrm{ml})$ of $5^{\text {th }}$ instar nymphs of $S$. gregaria.

\section{Discussion}

The current study investigated the effect of inoculation of $5^{\text {th }}$ instar nymphs of $S$. gregaria with $P$. aurantiogriseum and citrinin mycotoxin on the total haemocyte counts, differential haemocytes, the titer of phenoloxidase, which is considered as an insect immune barrier and total hamolymph protein. Haemocytes circulated in insect haemolymph were derived from stem cells that differentiate into specific lineages. However, certain haemocyte types are not common in all insects and differ among species (Meister and Lagueux, 2003). Haemocytes have been studied mostly in different orders (Chiang et al., 1988; Lavine and Strand, 2002 and Ribeiro and Brehelin, 2006). Little work has been reported in the available literature for Orthopterans, notably the acridids (Barakat et al., 2002; Tanani, 2010; Ghoneim et al., 2015). However, our results revealed fluctuations in the mean total haemocyte counts in treated insects. It decreased significantly at $1^{\text {st }}$ and $3^{\text {rd }}$ days and increased significantly at $5^{\text {th }}, 7^{\text {th }}$ and 
$9^{\text {th }}$ days post treatment in inoculated nymphs with $P$. aurantiogriseum and citrinin mycotoxin as compared to control. This increment may be due to the enhanced encapsulation of the toxic molecules through the process of melanization, melanin deposition during encapsulation which is commonly initiated by haemocytes circulation in the plasma (Rolff and Siva- Jothy, 2002; Nappi and Christensen, 2005). Moreover, it could be considered as an immune response against pathogen (Ordas et al., 2000). Fluctuation of the total haemocyte counts during fungal infection in the present study corresponded to similar results reported by Hung and Boucias (1992) and Zibaee et al. (2011). On the other hand, the decrease in total haemocyte counts in inoculated insects with citrinin mycotoxin may result from formation of nodules induced by fungal metabolites and inhibition of larval hematopoietic function or the cell proliferation (Zibaee et al., 2011; 2012). In addition, it may be attributed to the death of pathological cells by degeneration (Sendi and Salehi, 2010).

The insect haemocytes differentiated into 6 types as prohaemocytes, plasmatocytes, granulocytes, adipohemocytes, spherule and enocytoids (Chapman, 2013). The haemocytes of $5^{\text {th }}$ instar nymphs of $S$. gregaria were differentiated into 3 types as plasmatocytes, lymphocytes and granulocytes. This study calculated the percentage of each type according to the total haemocytes count in the three inoculated treatments, so the percentage of these types was convergent in all cases. Our results disagree with a lot of previously mentioned records for various insects; plasmatocytes and granulocytes played a role in phagocytosis of fungal spores (Zibaee et al., 2011). Secondary fungal metabolites (mycotoxins) suppressed phagocytosis along with nodule formation (Vey et al., 2002).

Phenoloxidase (PO) is a vital enzyme responsible for a number of crucial processes, such as defense, wound healing, sclerotization, and pigmentation. Phenoloxidase detected in both cuticle and haemolymph is derived from a pro-enzyme, prophenoloxidase. The PO cascade takes part in the melanization of haemocytes attached to the surface of the parasite (Pech and Strand, 2000). The present data showed fluctuation in the enzyme activity in haemolymph of $S$. gregaria inoculated with conidial suspension and citrinin mycotoxin as compared to at the five periods post treatment. Meanwhile, a comparison between the activity of phenoloxidase in insects inoculated by conidial suspension of $P$. aurantiogriseum and citrinin mycotoxin revealed non- significant decrease at $1^{\text {st }}$ and $5^{\text {th }}$ days and nonsignificant increase in $3^{\text {rd }}, 7^{\text {th }}$ and $9^{\text {th }}$ days post inoculated insects with citrinin mycotoxin. Initial enhancement of enzyme activity may be due to the consequences of the invasion of fungal pathogen into the host haemolymph. In locusts and cockroaches prophenoloxidase stored in haemocytes until a pathogen induces its release (Brehe'lin et al., 1986). Phenoloxidase generated quinones which may serve as toxic metabolites that might be harmful to the intruders (Ashida and Yamazaki, 1990). Products of PO activity, i.e. melanin and its oxidized precursors have been shown to have fungistatic activity (St. Leger et al., 1988). Several studies have shown that phenoloxidase levels are elevated in response to natural fungal infection or injection of fungal components (Gillespie et al., 2000). Invaders that are able to penetrate successfully into the insect hemocoel will face a battery of cell defenses, including the phagocytosis of small pathogens and the formation of multicellular layers that encapsulate large intruders by the blood cells. Decreased enzyme activity after infection might be due to suppression of host enzyme activity by releasing inhibitor factors by the invading fungal pathogen (Shelby et al., 2000). The decline may be also due to the immunosuppressive effect of fungal proteins or toxic metabolites. Certainly, destruxins prevent PO production by Locust haemocytes probably by destroying the cells that produce prophenoloxidase (Cerenius et al., 1990).

Proteins play an important role in the haemolymph of insects not only in specific transport functions, but also in their enzyme action. The high protein concentration is an indication of a greater metabolic activity of the tissue. They are not only responsible for the structure of the cell but also concerned with every function of the cell including respiration, catalysis of enzyme reactions, transport of materials, regulation of metabolism, movement and defense reactions (Rajitha and Savithri, 2013). Inoculation of $5^{\text {th }}$ instar nymphs of $S$. gregaria with $P$. aurantiogriseum and citrinin mycotoxin caused disturbance in the concentration of total haemolymph protein content as compared to the control in the $5^{\text {th }}$ instar nymphs inoculated with sterile water at different days post treatment. Gillespie et al. (2000) recorded reduction in total haemolymph protein concentration of adult $S$. gregaria during the course of infection with $M$. anisopliae. The loss of protein from host haemolymph during parasitism may be due to secretion of proteolytic enzymes from the parasite into the haemocoel of the insect and hydrolysis of the host's proteins. Helal et al. (2012) proved that $P$. aurantiogriseum secreted protease enzyme. An increment in mean total haemolymph protein content in the present work on the $9^{\text {th }}$ day post treatment 
with citrinin was in accordance with Barakat and Abokersh (2016). They reported that total haemolymph protein of $S$. gregaria infected with $B$. bassiana were significantly higher at the first three days post treatment, but lower at the $4^{\text {th }}$ day post treatment as compared with untreated insects. The observed decrease of total haemolymph protein contents following fungal infection may be attributed to fungal pathogenicity. Pathogens may cause a complete elimination of some haemolymph enzymes, soluble and sticky proteins, which may be involved in anti-fungal immunity. Some native proteins may be converted into lipoproteins or glycoproteins after infection. This could be attributed to intensive consumption of haemolymph proteins during growth and multiplication of the fungi, together with cessation of feeding observed on the infected insects (Sabbour, 2001; Seyoum et al., 2002 and Barakat and Abokersh, 2016). In contrary, the late increase of total proteins observed in this study at the $9^{\text {th }}$ day following infection may be caused by citrinin mycotoxin effect within the haemocoel. Also, the decrease in the mean of total haemolymph protein may explain the reason of the decrease in the haemocyte count.

\section{Conclusion}

Inoculation of conidial suspension of $P$. aurantiogriseum and its citrinin mycotoxin in $5^{\text {th }}$ instar nymphs of $S$. gregaria caused changes in total and differential haemocyte counts, phenoloxidase activity and disturbance of total haemolymph protein content during the treatment periods. These results suggested that entomopathogenic fungi and their mycotoxins secreted by them caused a disturbing action on the insect's haemolymph and may be interrupted by the hormonal balance or enzymatic hierarchy in nymphs, which can explain their effects on proteins and haemocytes.

\section{References}

Alkeridis, L.A. 2015. Application of Penicillium sp. as entomo-pathogenic fungi to control the red rust beetle Tribolium castaneum (Hbst.) (Coleoptera: Tenebrionidae). Bioscience Biotechnology Research, 13: 7-12.

Al-Mokhlef, A.A. 2008. Effect of some bio-agents on the desert locust Schistocerca gregaria (Forskål) in Egypt. M.Sc thesis, Entomology Department, Faculty of Agriculture, Ain Shams University, Egypt.

Arnold, J.W. and C.F. Hinks, 1979. Insect haemocytes under light microscopy technique. In: Gupta, A.P. (Ed.) Insect Haemocytes. Cambridge University Press, Cambridge, U.K.

Ashida, M. and H.I. Yamazaki, 1990. Biochemistry of the phenoloxidase system in insects: with special reference to its activation. In: Onishi, E. and Ishizaki, H. (Eds), Moulting and Metamorphosis. Scientific Societies Press, Tokyo, Japan 239-265.

Barakat, E. and M. Abokersh, 2016. Characterization of the haemolymph from Schistocerca gregaria adults after infection with entomopathogenic fungus Beauveria bassiana. Life Science Journal 13:79-87.

Barakat, E.M.S, W.S. Meshrif, and M.G. Shehata, 2002. Changes in the haemolymph of the desert locust, Schistocerca gregaria after injection of Bacillus thuringiensis. Journal of Egyptian Academic Society for Environmental Development, 2: 95-115

Bradford, M. 1976. A rapid and sensitive method for quantitation of microgram quantities of protein utilizing the principle of protein-dye binding. Analytical Biochemistry 72: 248-254.

Brehélin, M. and D. Zachary, 1986. Insect haemocytes: a new classification to rule out controversy. In: Brehélin, M. (Ed.) Immunity in Invertebrates. Springer Verlag, Berlin, Germany. 36- 48.

Cerenius, L., P.O. Thornqvist, A. Vey, M.W. Johansson, and K. Soderhall, 1990. The effect of fungal toxin Destruxin-E on isolated crayfish haemocytes. Journal of Insect Physiology, 36: 785-789.

Chapman, R.F. 2013. The Insects: Structure and Function. $5^{\text {th }}$ edition. Cambridge University Press, Cambridge, U.K.

Chavan, J.A., A.K. Chougale, and G.P. Bhawane, 2017. Toxicity of dimethoate and chlorpyriphos on haemocyte count in male Platynotus belli Fairmaire (Coleoptera: Tenebrionidae). Journal of Entomology and Zoology Studies, 5: 126-133

Chiang, S.A., Gupta, A.P. and Han, S.S. 1988. Arthropod immune system: I. Comparative light and electron microscopic accounts of immunocytes and other haemocytes of Blattea germanica (Dictyoptera: Blattellidae). Journal of Morphology, 198: 257-267. 
Gesraha, M.A. 2007. Impact of entomopathogenic fungi on the desert locust, Schistocerca greagria (Forskål). Egyptian Journal of Biological Pest Control, 17: 83-89.

Ghoneim, K., K. Hamadah, M. Amer, A. El-Hela, and A. Mohammed, 2015. Qualitiatives and quantitatives changes in the haemgram of desert locust, Schistocercs gregaria (Orthoptera: Acrididae) by extracts of Nigella sativa (Ranunculaceae). Journal of Advances in Biology, 7 : $1275-1292$.

Gillespie, J.P., C. Burnett, and A.K. Charnley, 2000. The immune response of the desert locust Schistocerca gregaria during mycosis of the entomopathogenic fungus, Metarhizium anisopliae var. acridum. Journal of Physiology, 46: 429-437.

Gupta, A.P. 1979. Haemocytes types: their structures, synonymies, interrelationships, and taxonomic significance. In: Gupta A.P. (Ed.) Insect Haemocytes. Cambridge University Press, Cambridge, U.K., 85-127.

Guzo, D. and D.B. Stolz, 1987. Observations on cellular immunity and parasitism in the tissok moth. Journal Insect Physiology, 33: 19-31.

Hashem, F.M., 2013. Biocontrol studies on the desert locust, Schistocerca gregaria by using entomopathogenic fungi. M.SC thesis in entomology, Zoology Department, Faculty of Science, Zagazig University, Egypt.

Hassanein, M.S. 1965. Laboratory and outdoor cultures and breeding of locusts and grasshoppers. FAO Publication 5/31901. 10

Helal, G., S. Rashed, E. Rashad, and F. Hashem, 2012. Fungi associated with the desert locust, Schistocerca gregaria (Forskål) and their laboratory potency against locust nymphs. Journal of Applied Sciences Research, 8: 3914-3920.

Helal, G., S. Rashed, E. Rashad, and F. Hashem, 2019. Pathogenicity of the entomopathogenic fungus, Penicillium aurantiogriseum and its mycotoxin (citrinin) against fifth nymphal instars of Schistocerca gregaria (Forskål). Middle East Journal of Applied Sciences, 9(3): 762-770.

Hicks, B.J., A.D. Watt, and D. Cosens, 2001. The potential of Beauveria bassiana (Hyphomycetes: Moniliales) as a biological control agent against the pine beauty moth, Panolis ammea (Lepidoptera: Noctuidae). Forest Ecology and Management, 149: 275-281.

Hung, S.Y. and D.G. Boucias, 1992. Influence of Beauveria bassiana on the cellular defense response of the beet armyworm, Spodoptera exigua. Journal of Invertebrate Pathology 60: 152-158.

Ishaaya, I. 1971. Observation on the phenoloxidase system in the armored scales Aonidiella aurantii and Chrysomphalus aonidum. Journal Biology Science Acadamic Egypt, 6: 1-10.

Jones, J. C.1962. Current concepts concerning insect hemocytes. American Zoologist. 2: 209-246.

Lavine, M.D. and M.R. Strand, 2002. Insect haemocytes and their role in immunity. Insect Biochemistry and Molecular Biology, 32: 1295- 1309.

Meister, M. and M. Lagueux, 2003. Drosophila blood cells. Cell Micrology, 5: 573-580.

Nappi, A.J. and B.M. Christensen, 2005. Melanogenesis and associated cytotoxic reactions: Applications to insect innate immunity. Insect Biochemistry and Molecular Biology, 35: 443459.

Ordas, M.C., A. Ordas, C. Belosa, and A. Figueras, 2000. Immune parameters in carpet shell clams naturally infected with Perkinsus atlanticus. Fish and Shellfish Immunology, 10: 597-609.

Pech, L.L. and M.R. Strand, 2000. Plasmatocytes from the moth Pseudoplusia includes induce apoptosis of granular cells. Journal of Inse Physiology , 46: 1565-1573.

Rai, D., V. Updhyay, P. Mehra, M. Rana, and A.K. Pandey, 2014. Potential of entomopathogenic fungi as biopesticides. Indian Journal of Science Research and Technology, 2: 7-13.

Rajitha, K. and G. Savithri, 2013. Phenoloxidase activity in haemolymph of silkworm Bombyx mori L. during the development of fungal pathogen Beauveria bassiana (Bals.) Vuill. International Journal of Recent Scientific Research, 4: 1391-1394.

Ribeiro, C. and M. Brehélin, 2006. Insect haemocytes: what type of cell is that? Journal of Insect Physiology, 52: 417-429.

Rolff, J. and M.T. Siva-Jothy, 2002. Copulation corrupts immunity: a mechanism for a cost of mating in insects. Proceedings of the National Academy of Sciences, U.SA. 99: 9916-9918.

Sabbour, M., 2001. Biochemistry of haemolymph of Earias insulana larvae treated with Bacillus thuringensis and Beauveria bassiana. Journal of the Egyptian- German Society of Zoology, 36: 19- 27. 
Sendi, J.J. and R. Salehi, 2010. The effect of methoprene on total hemocyte counts and histopathology of hemocytes in Papilio demoleus L. Lept. Munis Entomology and Zoology, 5: 240-246.

Seyoum, E., R.P. Bateman, and A.K. Charnley, 2002. The effect of Metarhizium anisopliae var acridum on haemolymph energy reserves and flight capability in the desert locust, Schistocerca gregaria. Journal of Applied Entomology, 126: 119-124.

Shelby, K.S., O.A. Adeyeye, B.M. Okot-Kotber, and B.A. Webb, 2000. Parasitism-linked block of host plasma melanization. Journal of Insect Physiology , 75: 218-225.

Siddiqui, M.I. and M.S. Al-Khalifa, 2012. Circulating haemocytes in insects: phylogenic review of their types. Pakistan Journal of Zoology, 44:1743-1750.

Leger, R.J.ST., R.M. Cooper, and A.K. Charnley, 1988. The effect of melanization of Manduca sexta cuticle on growth and infection by Metarhizium anisopliae. Journal of Invertebrate Pathology, 52: 459-470.

Tanani, M.A., 2010. Haemogram changes in the desert locust, Schistocerca gregaria (Othoptera: Acrididae) by different plants extracts from the wild plant Fagonia bruguieri (Zygoplyllaceae). Al- Azhar Bulletin of Science, 21: 67-96.

Vey, A., V. Matha, and C. Dumas, 2002. Effects of the peptide mycotoxin destruxin E on insect haemocytes and on dynamics and efficiency of the multicellular immune reaction. Journal of Innvertebrate Pathology, 80: 177-187.

Zeng, R., N. Guodong, W. Zhimou, M.A. Schuler, and M.R. Berenbaum, 2006. Toxicity of aflatoxin B1 to Helicoverpa zea and bioactivation by cytochrome P450 monooxygenases. Journal of Chemical Ecology, 32:1459-1471.

Zibaee, A., A.R. Bandani, and D. Malagoli, 2012. Methoxyfenozide and pyriproxyfen alter the cellular immune reactions of Eurygaster integriceps Puton (Hemiptera: Scutelleridae) against Beauveria bassiana. Pesticide Biochemistry and Physiology, 102: 30-37.

Zibaee, A., A.R. Bandani, R. Talaei-Hassanlouel, and D. Malagoli, 2011. Cellular immune reactions of the sunn pest Eurygaster integriceps, to the entomopathogenic fungus, Beauveria bassiana and its secondary metabolites. Journal of Insect Science, 11: 1-16. 